\title{
Strategic and risk management in cross country investment and operation
}

\author{
Zhenlin Ge $^{1, a, *}$, Changbiao Zhong ${ }^{1, b}$ and Yuanzhe Huang ${ }^{1, c}$ \\ ${ }^{1}$ Business School, Ningbo University, Fenghua Road, Ningbo, China \\ a gezhenlin@nbu.edu.cn, bhongchangbiao@nbu.edu.cn, 'c huangyuanzhe@nbu.edu.cn \\ *corresponding author
}

Keywords: cross-country, risks, strategic analysis, management.

\begin{abstract}
This essay mainly argues about risks existed in cross-country enterprises and the type ,analysis and selecting available strategies to reach higher economic adding .In the investment and operation activities of cross-country companies ,they face challenges and risks not only from external but from internal as well ,such as political risks ,economical risks ,environment risks and so on .Then ,this essay describes the strategy analysis and elections_—political factors ,economical factors ,social and cultural factors and technological factors consist of the outside strategy analysis factors. The cross country enterprises have to Select proper organization structure according to the company itself , Establish proper internal control system and implement effectively ,Select Proper strategic type in order to meet the needs of cross-country competition ,Precisely analyze the market environment and the capacity of the enterprise.
\end{abstract}

\section{Introduction}

The strategies of an enterprise play an essential role in the company`s development ,especially the increasing number of cross-country enterprises, which have a large scale but operating not only restrain from domestic market ,for many reasons such as the full capacity of domestic market ,the increasing labor prize ,and furthermore expand its`operating levels ,these companies tempt to operating abroad in order to get widely market proportions ,low material and labor costs .but there are both opportunities and risks existed in aboards ' market ,now ,This essay will describe risks existed in tie cross country competition ,and then raise strategy analysis and selections according to different strategy environment.

\section{Risks lies in cross-country operation companies}

\subsection{External risks}

External risks cannot be controlled by the company ,on the one hand, the enterprise may cause damage to its cross-country profit if the company ignores external risks; on the other hand ,external risks are various from areas and regions, which must be solved when a company tries to enter into the specific market

\subsubsection{Political Risks}

Political Risks Are mainly Led by The government and officers In order to protect domestic industry and company,Such as foreign currency Regulations ,Import restraints ,And tariff,What's more, many countries have the regulations of The lowest proportion of share holders And the organizational structures ,Even restraints on borrowing money from the foreign banks In order to get more foreign currency.These factors must be taken into account When a company try to enter into a foreign market,It will lead a large amount of Costs and loss Once a cross country company ignored them. It is also in sensor to be Care about Is the legal Of the laws and regulations That monitor the market,If they are equal ,especially equal to the foreign companies And foreigners, The cross country company may face a lower risks to enter into the Country's market,Including the legislation, The Implement Of the regulations Of the Aimed country's market. 


\subsubsection{Social and culture risks}

The culture and social risks Are widely influenced the cross country Company's investment and operating behaviors, On one hand ,Social customs and cultures Determined the preference of buyers That consist of populations Of the aimed country,If the cross country company cannot meet the needs of the Native buyers , It will lead to the company's Failure to capture the market,And even escape from the Specific foreign market.On the other hand The culture and social customs Have a great influence on the policy and regulations,Even the investment and operating behavior of the cross country company,If the company's behavior caused damage to the emotion of the native buyers, The peoples there Will erupt a resistance movement.Such as the mcdonald's Strategy of enter into the Indian market,The most Temptation opportunities of the Indian market Is a large amount of buyers Customers and the large amount of labors and employees,And mcdonald Only have to pay a low level salaries to the native employees Employed by the mcdonald's branch of the Indian market.And the large amount of buyers can get A large amount of profit to the mcdonald .However ,McDonnell neglect the important factors-It is the material of its hamburgers That makes Resistance of the native Buyers Because of the driven situations of the bulls ,The Indians refuse to Treat the bulls in a bad attitude And even slaughter While the main products material Is beefs. So The investment and operating of the Mcdonald's In the Indian market Have been deeply striked And then McDonald has escaped from the Indian market. Meanwhile, the McDonald Has reached great success in the market of China and the Europe Made seven percent increase of selling In the United States, domestic market. It is the Neglect of the culture and social behavior risks That lead to the failure of mcdonald's investment and operating to the Indian market.

\subsubsection{Risks from nature environment}

The enterprise will suffer from losses and operating failure Once it cause Serious damage to the natural environment,Such as the wood processing company Will be punished a large amount of Money After it pulled down many Woods And destroy a huge amount of forest, What's more A great number of Nature Resources is cannot be recovered,As for many Types of enterprise ,It can't processing is operating while the necessity Resources dry out,Such as mental processing factory.What's more, the enterprise should concerned about not only the damage to the nature,But the relationships of suppliers and buyers And other industrial As well,The attitude towards nature reserves is of an enterprise Have a great influence on its image In the public ,Such as Ecoson CO.LTD entered into the Brazil market,Purchased through a Brazil native company And then pulled down A great piece of the Amazon rain forest ,This operation caused serious public panic Of the global environment,And experts Have sustained about The importance of the Amazon rain forest-The lung of the earth,And then, the company has Raised public indignation For its behavior of pulling down the trees And In ruined the forest ,This has led to the resistance of the native inhabitants,unfriendship relationship between suppliers and buyers, And then later to low competitive in the Brazil market, Meanwhile The United States has legislation about prohibiting To Cut down the domestic forest And any company who cause damage to the forest will be heavily punished. So the Ecoson Company Lost its market position,Both in domestic and foreign.And then its share price collapsed And have to apply for Canceling its quality of training In the NASDAQ security trade Market.

\subsubsection{Technology risks}

The technology risk Include three aspects, The first one is The development and updating of a technology Can affect another company In the same industry, It will lead to more serious competition, The enterprises who have more advanced technology may take the advantage of market and resources to create more profits , So, in order to survive from the Assyrians market competition ,The other companies have to do more efforts to hold on its market situation. The second definition of the technology risk Is in the process of innovation Research and technology exploring,Because of the complexity of the technology itself and other relatives factors Which is full of uncertainty,May cause failure Innovations ,or Failure products ,or products that cannot meet the needs to the market buyers.A great amount of capital and resources must be Input in The process of innovation And research ,Once the innovation fail,The cross country enterprise may 
suffered a lot from capital loss. Last but not least, There is a saying goes The biggest risk is not change At all, The company will get out the market competition once it never innovation especially to cross country Companies

\subsection{Internal risks}

\subsubsection{Strategy Risks}

As the saying goes ,A wrong motivation And a wrong strategy Will lead to the failure of the operation. So the original risk of the inner risks Is the strategic risk. The strategy risks mainly includes the following aspects. The first one is Absence of definite developing strategy Or less powerful strategy implement,thus lead to the enterprise Hard to shape strength of competition And loose motivations and opportunities to developing itself.The next aspect of strategic risk is the radical Implement of developing strategy,Is specially to the cross country company,This radical of developing strength Might lead to the waste of resources And excessively expand And failure operating.

\subsubsection{Financial Risks}

For essence, the investment and operation of a company can be viewed as capital transferring from the investment of equipment and plant assets to receive costs and profits after finish the selling, beside above process, the company have to take the advantage of spare capital to invest any other project or financial production and instruments. With the different current and investment Policy via countries, cross country companies may face a generally conflicting capital environment, so its essential for cross country companies to absorb foreign currency and corporation regulations in order to resist financial risks.

As described above, the financial risks is mainly consisted of the follows: Risks of raising money, but foreign government often restrain the scale of foreign companies from domestic banks, or set a higher interest rate, so the cross company have to pay for a higher interest than native companies; Risks of investment is defined by the receiving capital cannot meet the expected return rate, furthermore effect the returns of operation outcome and cause damage to the capital resource of the enterprise. What 's more, cash flow in about the product selling, because of the difference of habit in market trading and regulations in trading, and the information asymmetry existed between companies lead to the absent of purchasers` financial ability, make bad debts of the company.

\section{Available strategic analysis, selection, and implement in cross country companies}

\subsection{Strategic Analysis}

\subsubsection{External Environment analyze}

Just as described above, the external environment analyze is essential for decision making that dominate the fate of the company. the external environment analyze include macroscopic environment analyze and industrial environment analyze.

The macroscopic environment analyze is consisted of political factors, economic factors, social factors and technological factors.

An enterprise can get its equal profit and protect the equity itself By using proper Legal and political Measures in a stable political and Legal environment .In other words The political environment is an essential Factor For an enterprise in the cross country competition,Such as industrial policy Tax Regulations And restrains about import and export in the domestic Companies .If an enterprise Meet the needs of the Industrial, tax and exporte and importe Policies in the Aimed country,The company Might invest And operate Easily in the aimed country's market.

The economic environment,Such as social economic structure,Level of economic development Economic regulations and the circumstances of contemporary economic. The economic factors has a specific influence On the Investments and operation of a cross Country company Compared with political environment. 
Next, the social and cultural environment Which reflected the social structure of the habit of relief and Lifestyle What's more, the size of populations ,The Conventional culture Which determined the acceptable About the cross country Company's production In the aimed market Such as selling beef to the market of India Or Selling beef to the market of China. Last but not least, the technology environment. Including a country's policy to support the technology and innovations. The scientific technologies level And the tendency of the the technology development.

The next aspect of analyzes Is so-called industrial environment analize, Which include life time of the period of Products,And competition power existed in the competition environment,Such as the materials provider,Buyers of the productions,Alternative protections existed in the market,And potential competitors who try to enter into the market.Cross country Enterprise will faced more serious challenges If The aimed market Have more competitors In the same industry,So it is with The capacity of bargain Carried by providers and buyers, The company will face more challenges If the buyers and providers while more powerful Capacity of bargain.So a cross country coming must Weight Any aspect of Competitive power When it is time to enter into An alien market aboard

\section{Dealing with cross country competition-from the perspective of risk and Strategic manage ment}

Select proper organization structure according to the company itself: proper organization structure that adapt to the cross country companies can improve the operating efficiency of the company, such as department set by products procedure or areas ,proper organization structure can also reduce management cost, increase communications via areas where the company set its branches in.

Establish proper internal control system and implement effectively :The internal control system stress on implementing while strategy and risk analysis stress on searching .Powerful implementing of internal controlling can increase operating effectiveness and reduce cheating, whats more keep all components of the large-scaled cross-country companies`efficiently working, enhance the ability of resisting any aspects of risks

Last but not least, elect Proper strategic type in order to meet the needs of cross-country competition ,only in this way can the cross-country companies capture more markets steep by step

\section{Acknowledgement}

National Natural Science Foundation of China: Study on the coordination mechanism and policy of inward FDI and outward FDI strategy (71673182)

\section{Reference}

[1] Harold F. Williamson , Alfred D. ChandlerStrategy and Structure: Chapters in the History of the Industrial Enterprise [J].Technology and Culture, 2015, Vol.5 (1)

[2] Dichmont C.M,Deng A.R,Punt A.E.et al.Management strategies for short lived species:The case of Australia‘s Northern Prawn Fishery. Fisheries Research . 2016

[3] Axel Volkey,Darren Suanson,Klaus Jasob,Francois Brefha,Laszlo Pinter.Coordination, Challenges and Innovations in 19 Nation Sustainable Development Strategy. World Development . 2016

[4] Lafferty W,Meadowcraft J.Implementing sustainable development:Strategies and initiatives in high-consumption societies. . 2013 